\title{
THE IMPACT OF FOREST FIRE ON FOREST COVER TYPES IN MONGOLIA
}

\author{
Nandin-Erdene Geserbaatar ${ }^{1,2}$, Elbegjargal Nasanbat ${ }^{1,2}$, Ochirkhuyag Lkhamjav ${ }^{2}$ \\ ${ }^{1}$ Information and Research Institute of Meteorology, Hydrology and Environment, Juulchiny street-5, \\ Ulaanbaatar 15160, Mongolia \\ nandia0910@gmail.com; n.elbegjargal@gmail.com \\ ${ }^{2}$ Mongolian Geospatial Association, P.O.Box-24/38, Ulaanbaatar 15141, Mongolia \\ ochirkhuyag@geomedeelel.mn, mongeoinfo@gmail.com
}

\section{Commission III, WG III/7}

KEY WORDS: Forest Fire, Landsat imagery, Forest cover type, Image classification

\begin{abstract}
:
The objective of this study was the impact of forest fire on forest cover types. This study has identified non-forest and forest area that has seven forest class are included with cedar, pine, larch, birch, birch-pine mixed, birch-larch mixed and cedar-larch mixed, additionally, remote sensing imagery is applied. In contrast, Landsat imagery has been used several classification approaches. Moreover, the current classification has developments in segmentation and object-oriented techniques offer the suitable analysis to classify satellite data. In the object-oriented classification approach, images cluster to homogenous area as forest types by suitable parameters in some level. The accuracy analysis revealed that overall accuracy showed a good accuracy of determination (86.33 percent in 2000 and 93.75 percent in 2011) with regard to identify of the forest cover and type. Furthermore, these results suggest that the Landsat TM and ETM+ data can reliable detect the forest type based upon the segmentation and object-oriented techniques. In generally, our study area is high-risky region to forest fires. It is higher influence to forest cover and tree species and other ecosystems. Overall, wildfire of impact results showed that 25239 ha of forests were changed to burnt area and 52603 ha forests were changed to grassland.
\end{abstract}

\section{INTRODUCTION}

Mongolia is landlocked country between Russia and China, and a territory area is 1.56 million $\mathrm{km} 2$. It covers six climatic zones, including that desert, desert steppe, steppe, forest steppe, boreal forest and montane (World Bank, 2004). The forest of Mongolia is growing terrestrial dry and harsh climate, therefore forest capacity, natural growth, and resilience are absolutely low, and very easily lost ecological balance, because of natural and human impacts, including dryness, fire, pesticide and disease (Ch.Dorjsuren, 2007). According to the National Statistic Office, NSO (NSOSTAT data 2000), the boreal forest and forest steppe zones contain a coniferous component composed of Siberian larch (Larix siberica), Scotch pine (Pinus sylvestris) and Siberian pine or cedar (Pinus siberica), and a smaller broad-leafed component composed primarily of birch (Betula platyphylla), aspen (Populus ttermula) and poplar (Populus diversifolia). Over $90 \%$ of northern forests covers within seven provinces: Khuvsgul (29\%), Selenge (16\%), Bulgan (14\%), Kentii (11\%), Tuv (10\%), Arkhangai $(8.5 \%)$ and Zavkhan (5\%). Mongolia has a typical continental climate, with hot summers (temperature up to 410C) and cold winters (temperatures to $\cdot 530 \mathrm{C}$ ) and rainfall is relatively low, varying from $50 \mathrm{~mm}$ in the southern desert region, to 450 $\mathrm{mm}$ in mountain areas, with $80 \% \sim 96 \%$ falling in the warm period from May to September (Erdenetuya, 2012). According to Erdenetuya (2012), about 56 per cent of the country's total area is located in a zone exposed to forest and grassland fires and a considerable fraction (98.5\%) of the country's territories covered with forests are in a zone assessed as of highest fire risk. Wildfires constitute a major that determine spatial and temporal dynamics of forest ecosystems (Goldammer, 1999). Historically, fire was the most dominant disturbance factor in forests across the Mongolia, and strongly influenced spatial temporal dynamics of forest ecosystems (Chuluunbaatar, 1998).

Thus, fire is a natural and important component of these forest systems. The nature of wildfires may be changing in these systems, however, as a result of climate change, past management, and other anthropogenic causes (MNE, 2014). Moreover, the amount of wood available to meet demands by households and industry are increasing (NSOSTAT review, 2015). The government has recognized that wood imports are necessary to meet supply shortfalls and to discourage illegal logging. Hence customs duties on some types of wood and timber imports have been removed. The country's forest resource is not very rich in extent or quality, covering an area of 17.5 million ha on the southernmost fringe of the Great Siberian forest and some mountain ranges western and northwestern part of Mongolia territory (J. Tsogtbaatar, 2004). Although in the Law on Forests is required to implement detailed research again on the forest database which changes periodically every 10 years, we cannot monitor the forest areas' changes depending on current forest research equipment and technology, funds and capacity. For the Mongolian forest inventory a use of old aerial photography from 1970 s to 1980 s data and a visual estimation in the fieldwork are necessary.

The forest area has decreased by 1.2 million ha during the last 30 years from 1974 to 2006, but environmental and human impacts such as, burnt forests, logging, open forests are as increased by 3.2 million ha during the period (MNE, 2006). According to FAO statistics, present forest resources of the country indicate that Mongolia has a small amount of forest resources that have been decreased by human impacts, fires, insects and illegal logging (MNE, 2001). Moreover, it was noted that the occurrence of wildfire and distribution of forest pests were increased which statistic from 2010-2013 mention report of the nature and environmental of Mongolia (S. Bayarkhuu, 2014). The forest functions map, wildfire risk assessment and forest management plan. According to researchers, geospatial technology approaches and data are mapped the forest functions using GIS (B. Ochirsukh et al., 2011); wildfire risk map using decision support system (Elbegjargal and Ochirkhuyag, 2016) Therefore, we need to establish and expand a harmonized approach with application of geo-informatics for determination of forest resources in order to use for its management at decision 
making/planning and management level. However, the use of high-resolution data has a limit in the process of pixel orientated classification mainly adopted to medium spatial resolution image according to (Blaschke and Strobl, 2002; Hofmann, 2001; Limp, 2002; De Jong et al., 2000). Also, it was noted that new image classification approach, the method of object-oriented classification which thought as important the spatial-relations of the pixels which compose an image attracts attention. Since it has the classificatory function which gave the hierarchical structure that image analysis software, eCognition (Definiens Imaging, Germany) which has adopted this classification method in this object-oriented classified a forest and the classified object into a coniferous forest and a broadleaved forest further after classifying into a forest and non-forest first, it can be identify that it is suitable for the detailed classification of a forest area (Ursula et al., 2004). Also, we needed to identify immediate forest change detection. For this purpose, high spatial resolution satellite data is necessary and it would be used for forest inventory, for forest mapping and forest change detection. Forest cover types, disturbance regime maps and forest change detection maps will be developed in order to inform government agencies on the status of forest resources. Current image is very important for mapping and change detection analyze.

The objective of this study aimed to determine the fire impacts on forest types and forest cover changes using Landsat TM and ETM+ data. Moreover, to implement specific objective are that to develop forest cover classification scheme from satellite data interpretation and forest distribution scope, the evaluate forest cover change from different temporal scales and to determine how the forest fire influences the forest cover types and their changes.

\section{STUDY AREA}

The study area, Eruu soum, locates in the Selenge province in the northern part of Mongolia, approximately $360 \mathrm{~km}$ from capital of Ulaanbaatar. The Eruu soum's forest ecosystem is the sub- tundra and forest steppe zone (N 490-500, E 1060-1080), which covers approximately 839420 hectares, which forest area has covered about $96.1 \%$ of the land (Figure 1). The main forest types dominate by birch, aspen, cedar, fir, larch and pine. The study areas are in the elevation range of 573 to 2126 meters above sea level extracted from the 30-m resolution ASTER GDEM v2 was downloaded https://www.jspacesystems.or.jp/ersdac/GDEM/E/4.html.

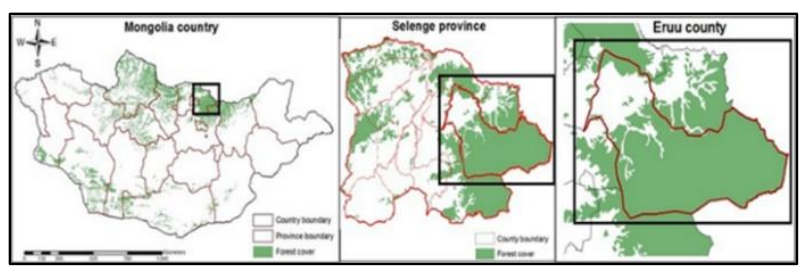

Figure 1. Study area

The mean annual temperature of about $7.00 \mathrm{C}$ while the mean monthly temperature ranges from $-220 \mathrm{C}$ to $190 \mathrm{C}$. A maximum temperature of $36.40 \mathrm{C}$ is recorded in June, and minimum temperature of $-40.10 \mathrm{C}$ is recorded in January. Annual amount of precipitation is $276 \mathrm{~mm}$ and most of it falls between May and September. (Azzaya, D., Munkhzul, D., 2007).

In the case of the burnt area statistic, during 2007-2009 that period has high frequently in region of study area illustrated in figure 2 .

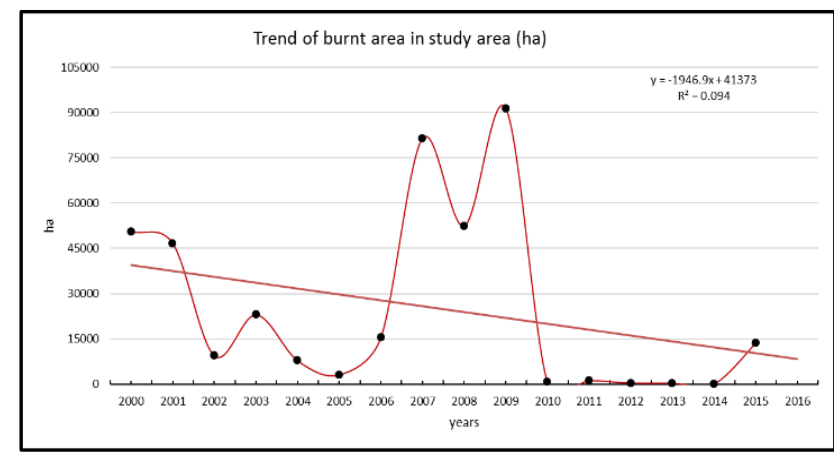

Figure 2. Burnt area trend of study area

In figure 2, during 15 years' number of burned area has been decreasing that period. However, in the whole territory has steppe fire occurrence is higher than forest fire.

\section{MATERIALS AND METHODS}

We have been used Definiens Developer software (formerly eCognition) to clusters and post-classification objects in the satellite image.

\subsection{Object-oriented image analysis}

The object-oriented classification does not operate directly on single pixels, but image objects which refer to homogeneous, spatially contiguous regions obtained by dividing image, namely image segmentation. Image segmentation is a preliminary step in object-oriented image classification, and the segmentation technique can be grouped into three types: thresholding/clustering, region based, and edge based. That techniques can be found in according to (Jing Quian, Qiming Zhou and Quan Hou, 2007) and (Fu and Mui, 1981; Haralick and Shapiro, 1985).

Overall, the object-oriented approach and the image analysis process are divided into the two principal workflow steps, segmentation and classification methods have been intensively used for a large number of environmental applications. Examples for such applications includes: image classification based on higher resolution satellite image (Kanta Tamta et al. 2015 and Sun Xiaoxia et al. 2005) and land cover change (Michael J. et al. 2012); forest types classification (S.Shataee et al. 2004); Productive Fossil Localities (Charles Emerson et al. 2015) and many more. These applications have mostly been implemented using high resolution remote sensing imagery (Stanislaw Lewinski et al. 2014). The different spatial working steps for the image classification and with burned area time series analysis of remote sensing data are represented in figure 3. 


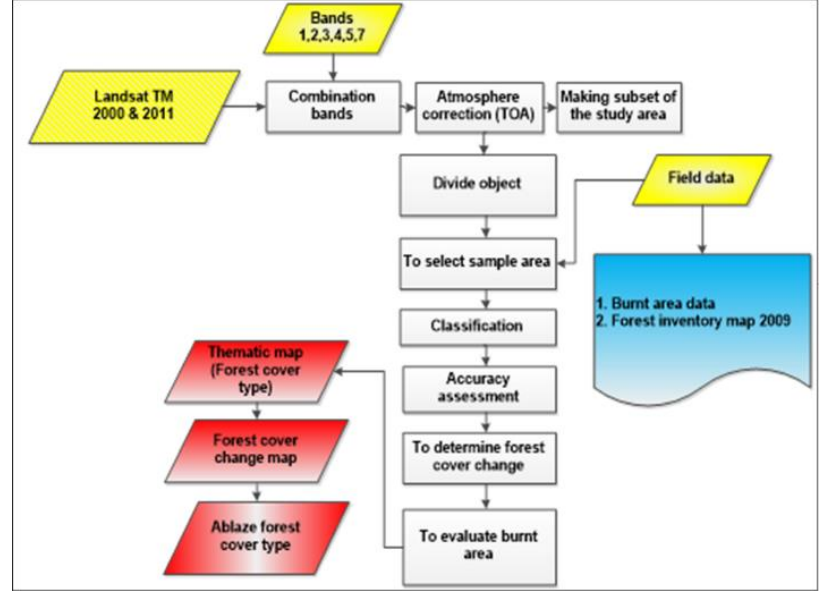

Figure 3. Diagram of the methodological workflows

\subsection{Datasets}

In order to investigate the Landsat-5 Thematic Mapper (TM) and Landsat-7 Enhanced Thematic Mapper Plus (ETM+) images were acquired in the early 2000 s and 2011 were used (14 April 2000, 13 September 2000 and 20 September 2011) for path 131 row 25-26, respectively. In order to reduce scene-to-scene variation related to sun angle, differences in atmospheric condition. In addition, cloud cover of images is minimal in all scenes. Digital number values of data converted to radiance, and ground-leaving reflectance translated from radiance using the $6 \mathrm{~S}$ algorithm (Vermote et al. 1997).

In addition, we were collected thematic maps and ancillary datasets (Table1.) A combination of image processing software: ArcMap, ERDAS Imagine, ENVI and Definiens developer software applied throughout the all process.

Table 1. data collection

\begin{tabular}{llll}
\hline Satellite & Sensor & Date acquired & $\begin{array}{l}\text { Spatial } \\
\text { resolution } \\
(\mathrm{m})\end{array}$ \\
\hline Landsat & ETM+ & $\begin{array}{l}14 \text { April } 2000 \\
13 \text { September }\end{array}$ \\
Landsat & ETM+ & 30 \\
& 2000 & 30 \\
& 20 September \\
Landsat $\quad$ TM & 2011 & 30 \\
\hline Thematic data & \\
\hline Topographic maps \\
Forest inventory map 2009 \\
\hline Ancillary data \\
\hline $\begin{array}{l}\text { Forest fire information by MODIS 2000 - 2016 (burnt } \\
\text { area) }\end{array}$ \\
Forest statistic data 2007 \\
\hline
\end{tabular}

We have been used burnt area distribution image by MODIS and hectares in each year from 2000 to 2011 for data analysis in this study has been shown in figure 4 .

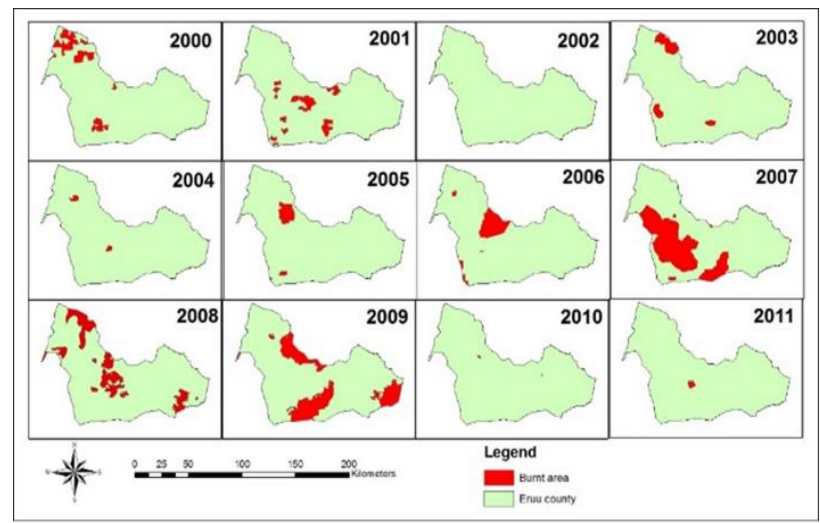

Figure 4. Burnt area distribution image by MODIS image of study area (2000 to 2011)

According to the fire statistics of 2000-2011, biggest fires of 106500-197200 hectares in the range between 2007-2009 were occurred in study area.

\section{RESULT AND DISCUSSION}

Overall, the study area is representative of the southern boreal forest of Serbia. We have been generated their forest type of distribution map highlighted two year 2000 and 2011.

That classified maps were based on nearest neighbor of objectoriented classification approaches. It will be more realistic that it is accuracy be compared to the traditional pixel-based classification (Akif Mohammed Al Fugara et al. 2009). Figure 5 and 6 shows the result of the classified satellite images in 2000 and 2011. These images identified about 14 cover classes with a description of 9 vegetation cover including 8 forest cover types cedar, pine, larch, birch, shrub and three types of mixed forest have been used 30 meter spatial resolution Landsat TM and $\mathrm{ETM}+$ data.

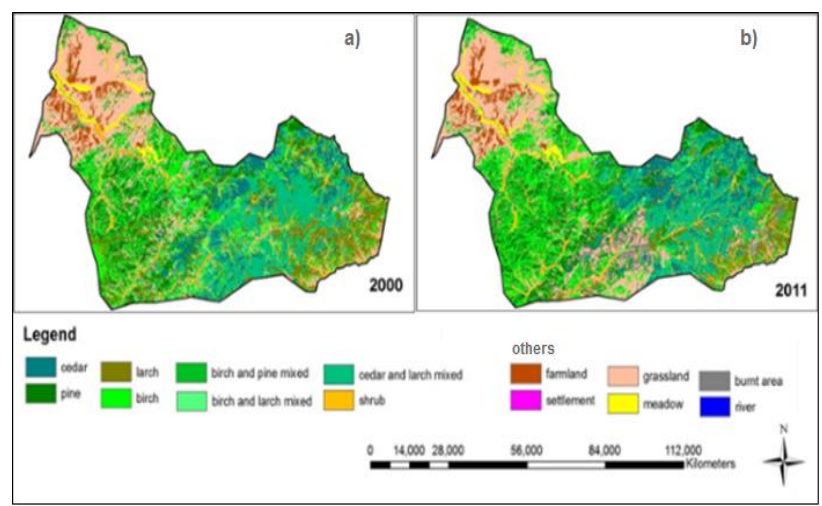

Figure 5. Classified for the forest types using satellite imagery a) forest type 2000 and b) forest type 2011. Which represented forest types (cedar, pine, larch, birch, shrub, birch-pine mixed, birch-larch mixed and cedar-larch mixed. In general, pine is dominant in birch and pine mixed forest, larch is dominant in birch and larch mixed forest. After the burning pine and larch, they can be replaced by birch in naturally and rapidly. In addition, occurrence of forest fires depends on forest types, precipitation distribution and availability of fire sources. (Goldammer., 2007). 
The central and south area of Eruu soum was affected by fires in 2007-2008 and this burnt area was clearly detected by satellite imagery. The forest cover type changes replaced by other forest cover types after burning. Also, vegetation cover types were replaced with grass land and barren land in 2011. The results shown in figures 6 and 7.

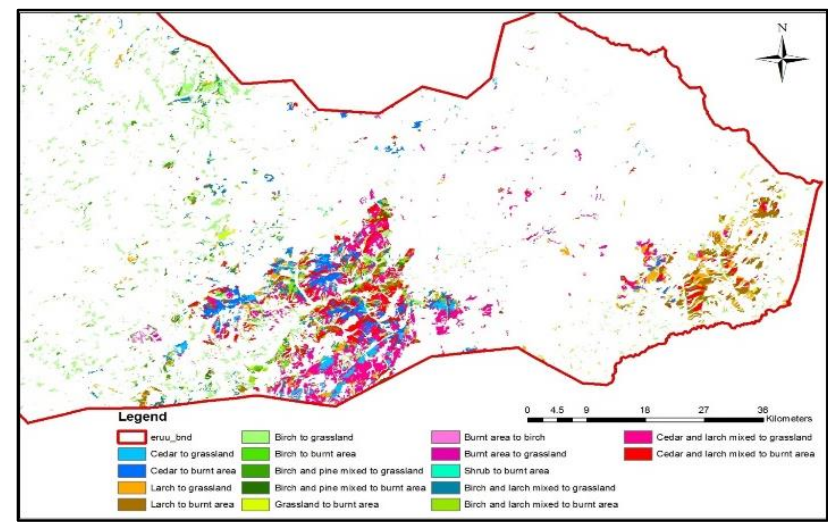

Figure 6. Forest type changes 2000 and 2011

About 17211-hectare area covered by birch and 16128-hectare cedar and larch mixed area were replaced by grassland area. Its illustrated in figure 7.

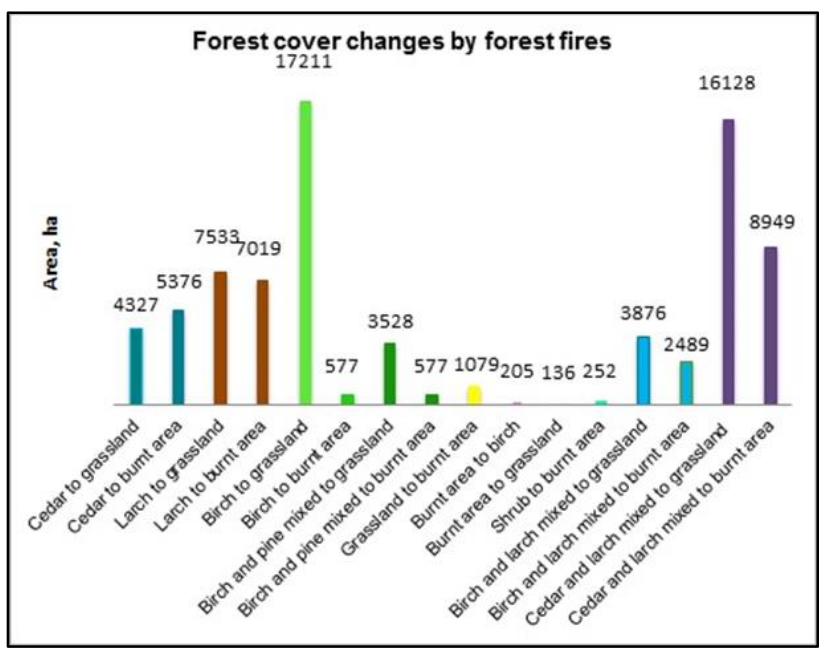

Figure 7. Forest cover and type change by forest fire

Totally 25239 ha of forests were changed to burnt area and 52603 ha forests were changed to grassland. Therefore, forest type in central and east parts of study area in 2000 was changed to grassland and birch area in 2011 due to forest fires. The forest cover area has decreased by $5.03 \%$ and non-forested area has increased by $11.9 \%$ in 2011 compared to 2000 . According to our study results, larch was extremely decreased by $10.4 \%$ due to forest fires in Eruu soum area. However, readers can pay attention on an accuracy of our used methodology that is approximately $80 \%$. Increases in cedar by $22.4 \%$ may relate with classification methodology because cedar can be mixed with other class type. It has represented change of forest types shown in table 2.
Table 2. Change of forest types

\begin{tabular}{llll}
\hline Land classes & 2000 & 2011 & Change \% \\
\cline { 1 - 2 } & \multicolumn{2}{c}{ Area unit (hectares) } & \\
\cline { 2 - 3 } Cedar & 51439 & 66353 & 22.4 \\
Pine & 96925 & 104137 & 6.9 \\
Larch & 98232 & 88672 & -10.4 \\
Birch & 110734 & 127771 & 13.3 \\
Birch and & & & \\
pine mixed & 36868 & 64532 & 42.8 \\
Farmland & 20976 & 20829 & -0.7 \\
Settlement & 236 & 284 & 16.8 \\
Grassland & 184172 & 188676 & 2.3 \\
Meadow & 14982 & 16875 & 11.2 \\
Burnt area & 617 & 27744 & 97.7 \\
Barren land & 4651 & 4205 & -10.9 \\
River & 2210 & 2097 & -5.3 \\
Shrub & 45635 & 41413 & -9.2 \\
Birch and & & & \\
larch mixed & 31895 & 30214 & -11.1 \\
Cedar and & & & \\
larch mixed & 140196 & 118997 & -15.1 \\
\hline
\end{tabular}

\subsection{Accuracy assessment}

Accuracy assessment is very important for verification of classification results. In mathematics, the computation of probable error of classification is very complicated. But in practice, we often assess the classification accuracy by means of examining samples and computing the error matrix from the statistical comparison between each interpretation and the ground data. The result of the object-oriented classification of the Landsat imagery were compared, used a forest inventory map of 2009, higher resolution satellite image in Google-Earth, digital elevation model and burnt areas statistic data. Also, we used a random method of systematic, then 256 points were selected into study area. The results of the accuracy assessments and the Kappa statistics of both image classifications are presented in table 3 and table 4 . In order to evaluate the usefulness of geographic data for forest cover type classification, we also used object-oriented classification method to Landsat images.

Table 3. Error matrix for the overall classification in 2000

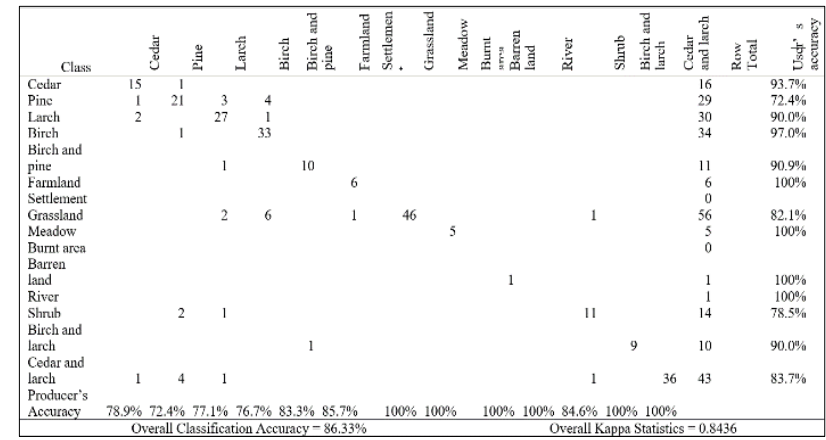

Table 4. Error matrix for the overall classification in 2011 


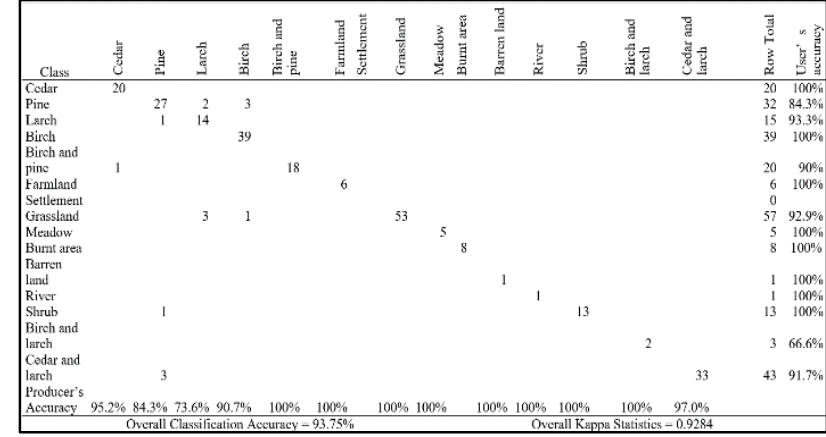

The overall accuracy achieved by the object-oriented classifications are $86.33 \%$ in 2000 and $93.75 \%$ in 2011 . The kappa coefficients are found to be 0.8436 in 2000 and 0.9284 in 2011 which are high, especially for a classification containing as many as fourteen types of land covers.

\section{CONCLUTIONS}

The study operates the ability of remote sensing technology, Landsat TM and ETM+ data, to classify forest cover types in the two-different date imagery using object-oriented image analysis methods. Consequently, nearest neighbor approach is appropriate the results of forest types in the study area. Moreover, the study is identified non-forest and forest area that has seven forest class are included with cedar, pine, larch, birch, birch-pine mixed, birch-larch mixed and cedar-larch mixed. The overall accuracy of the forest type maps was $86.33 \%$ in 2000 and $93.75 \%$ in 2011. The kappa coefficients have been found to be 0.8436 in 2000 and 0.9284 in 2011 which are highly significant, especially for a classification containing as many as fourteen types of land covers.

According to the fire statistics of 2000-2016, biggest fires of 106500-197200 hectares' area occurred over study area during 2007-2009. In generally, our study area is high-risky region to forest fires. It is very higher influence to forest cover and tree species and other ecosystems. Overall, wildfire of impact results showed that 25239 ha of forests were changed to burnt area and 52603 ha forests were changed to grassland.

\section{ACKNOWLEDGEMENTS}

We are glad the Remote Sensing Division of the Information and Research Institute of Meteorology, Hydrology and Environment of Mongolia and NUM-ITC-UNESCO Space Studies and Remote sensing Laboratory for supporting this study. We would like to express special thanks to S. Khudulmur, senior remote sensing expert, M. Odbayar, Head of remote sensing division, Dr. M. Erdenetuya and Dr. R. Tsolmon and Dr. J. Tsogtbaatar, who are supervisor of the first author' master study.

\section{REFERENCES}

Azzaya, D., Munkhzul, D. 2007. Agro-climatic resources of central region of Mongolia, climatic resource central region, and its change, Ulaanbaatar.

Bayarkhuu, S., 2014. Report of Nature and Environmental of Mongolia, Ulaanbaatar, pp.83-85.
Blaschke, T., Strobl, J., 2002. What's wrong with pixels? Some resent developments interfacing remote sensing and GIS

Campbell, M., J., Congalton, R.G. 2012. LANDSAT-Based Land Cover Change Analysis in Northeastern Oregon's TimberResource-Dependent Communities. American Society of Photogrammetry \& Remote Sensing 2012 Annual Conference.

Chuluunbaatar, T., 1998. Fire in forest ecosystem of Mongolia.

Dorjsuren, Ch., Bolor, U., 2007. Forest resource, protection, utilization and reforestation. Proceeding of Environmental, Ulaanbaatar, pp.78-85.

Emerson, C.; Bommersbach, B.; Nachman, B.; Anemone, R. 2015. An Object-Oriented Approach to Extracting Productive Fossil Localities from Remotely Sensed Imagery.Remote Sens.7.

Erdenetuya, M., 2012. Fire occurrence and burning biomass statistics in Mongolia. The Proceedings of 33rd Asian Conference Remote Sensing.

Fu, M., Mui, C. 1981. A survey on image segmentation.Pattern Recognition 13, (1). 3-16.

GeoBIT/GIS, 2001. J. Spatial Information Decision making, No.6. 12-17.

Goldammer, J.G. 2007. The Forest Fire Situation in Mongolia. International Forest Fire News No. 36, 46-66.

Gyanesh, Ch., Markham, B. 2009. Summary of current radiometric calibration coefficients for Landsat MSS, TM, ETM+, and EO-1 ALI sensors. Remote Sensing of Environment. 113. 893-903. 10.1016/j.rse.2009.01.007.

Haralick, R.M., Shapiro, L.G. 1985. Image segmentation techniques. Computer Vision Graphics and Image Processing. $29,100-132$.

Lewinski, S., Zbigniew, B., Konrad, T. 2014 Application of an Object-Oriented Method for Classification of VHR Satellite Images Using a Rule-Based Approach and Texture Measures. Land Use and Land Cover Mapping in Europe. Springer Netherlands. 193-201.

MNE, 2001. Report of Nature and Environmental of Mongolia, Ulaanbaatar, No248, 1-2.

MNE, 2006. Annual report of Forest and Water research center, Ulaanbaatar.

Nasanbat, E. and Lkhamjav, O. 2016.Wild Fire Risk Map in The Eastern Steppe Of Mongolia Using Spatial Multi-Criteria Analysis, Int. Arch. Photogramm. Remote Sens. Spatial Inf. Sci., XLI-B1, 469-473, https://doi.org/10.5194/isprs-archives-XLIB1-469-2016.

Ochirsukh, B., 2011. GIS mapping for forest fire risk zone in Selenge, Mongolia. Korea Geospatial Information Society Conference. 53-56

Qian, J., Qiming, Z., Quan, H. 2007. Comparison of pixel- based and object-oriented classification methods for extracting built-up areas in arid zone. ISPRS Workshop on Updating Geo-Spatial Databases with Imagery \& The 5th ISPRS Workshop on DMGISs. Vol. 36. No. 4/W54. 
Shataee, S., Kellenberger, T., Darvishsefat, A.A. (2004) Forest types classification using ETM+ data in the north of Iran / comparison of object-oriented with pixel-based classification techniques.

Shataee, S., Kellenberger, T., Darvishsefat, A.A. 2004. Forest types classification using ETM+ data in the north of Iran/Comparison of Object-oriented with Pixel-based Classification Techniques. Proceedings of the International Society for Photogrammetry and Remote Sensing, XXth ISPRS Congress.

Murakami, T. 2004. Seasonal variation in classification accuracy of forest-cover types examined by a single band or band combinations. $J$ For Res 9,211-215. https://doi.org/10.1007/s10310-004-0075-1

Tamta, K., Bhadauria, A.S., Bhadauria, H.S. 2015. ObjectOriented Approach of Information Extraction from High Resolution Satellite Imagery. IOSR Journal of Computer Engineering.1.17.47-52.

Ursula C. B., Peter, H., Gregor, W., Iris, L., Markus, H. 2004. Multi-resolution, object-oriented fuzzy analysis of remote sensing data for GIS-ready information. ISPRS Journal of Photogrammetry and Remote Sensing. Volume 58, Issues 3-4. 239-258.

Vermote, E.F., Tanre, D., Deuze, J.L., Herman, M., Morcette, J. 1997. Second Simulation of the Satellite Signal in the Solar Spectrum, 6S: an overview, IEEE Transactions on Geoscience and Remote Sensing.vol. 35. no. 3.675-686.

Xiaoxia, S., Jixian, Zh., Liu, Zh. 2005. A comparison of objectoriented and pixel-based classification approachs using quickbird imagery. 